ORIGINAL PAPER

\title{
Regional Anaesthesia in a Combat Setting
}

Bala Chandran NAMBIAR', Bhavna PAHWA², Moumita GHATAK ${ }^{3}$

\begin{abstract}
Background: Recent advances in combat casualty care have contributed significantly to higher survival rates in previously fatal injuries from military trauma. However, most of the literature comes from international data during Operation Enduring Freedom and Operation Iraqi Freedom. Despite having conflicts, counter insurgency operations spanning over decades, very few studies in Indian scenario have analyzed injuries related to Combat and Military Trauma. Method: A retrospective observational study was done based on the records of management of military trauma cases in a zonal hospital deployed in an operational area. All trauma/ combat casualties over a one year period from Oct 2018 to Oct 2019 were included and data was segregated based on type of mechanism of trauma, limb injuries involved, and choice of anaesthesia given based on type of surgery. Results: Total 371 combat casualties were included in the study, maximum patients had splinter injuries with grenade blast (43.4\%), followed by gunshot wounds (39.9\%). Other injuries included mine blast (11.3\%) and miscellaneous including road traffic accidents (5.4\%). Due to predominant involvement of limbs, regional anaesthesia was used most commonly (78\%) and general anaesthesia was used only in $23.7 \%$ of cases. Conclusion: In our study maximum casualties were peripheral limb injuries both upper and lower limbs. Regional anaesthesia, peripheral nerve blocks for upper limb injuries and sub arachnoid block for lower limb injuries, were more commonly used in comparison to general anaesthesia (GA), while injuries involving body regions other than limbs were performed exclusively under GA.
\end{abstract}

Keywords: anaesthesia, combat, military, injury.

\section{INTRODUCTION}

There is an ongoing worldwide epidemic, with respect to the use of opioids for pain management in the setting of trauma, to which military and combat trauma is also not excluded. Opioids are generally the first choice of analgesics in patients with multiple injuries, but they are associated with multiple adverse effects, including nausea, vomiting, constipation, delirium, vasodilation and hypotension (especially in hypovolemia), respiratory depression, pruritis and immunosuppression and hence there is an increased requirement for nursing care to monitor the patient. In various studies opioid use has also been associated with increased length of hospital stay. Presently, multimodal approach for pain relief using regional anaesthesia instead of single drug opioid therapy is becoming the standard of care in routine elective surgeries. This has resulted in a significant decrease in opioid-related adverse effects. Similar multimodal approach is required to be adopted for better pain management of the combat casualties and improving their long term outcomes.

Mechanism of injury is an important consideration factor in epidemiological analysis of combat and military trauma. Due to improvements in battlefield equipment including cataphract and continued advances in trauma medicine, modern military combatants have a
1 Department of Anaesthesiology, Base Hospital, Srinagar, India ${ }^{2}$ Department of Anaesthesiology, Military Hospital, Gangtok, India

${ }^{3}$ Department of Anaesthesiology, Military Hospital, Amritsar, India
Corresponding author.

Bhavna PAHWA, 178 Military Hospital, Gangtok, Sikkim, c/o 99 APO, India.

E-mail: pahwabhavna@yahoo.co.in 
significantly higher survival rates due to lesser incidences of torso injuries. However, incidence of extremity injuries have increased proportionately. Regional anaesthesia techniques, including peripheral nerve blocks, help in managing pain adequately and effectively which is specific to the site of injury and they are also devoid of any systematic opioid-related adverse effects.

During the last twenty years, acute pain management facilities have modified according to the requirements of ever-changing operational combat scenarios. Non-opioid analgesia like ketamine and regional anaesthesia are now indispensable and essential components of pain management for combat casualties. Anaesthesiologists working in operational scenarios and providing care to the combat casualties, need to be competently trained and be proficient to adequately deliver multimodal analgesia techniques, to establish better standards of military trauma care.

Regional Anaesthesia (RA) has a possible advantage to prevent central sensitization and the subsequent chronic pain syndrome by blocking afferent pathways and decreasing acute pain intensity. In the combat environment, patients who received indwelling continuous peripheral nerve catheters near the time of traumatic amputation had significant pain relief in the affected limb and lesser incidence of neuropathic pain, compared to those who did not receive any intervention. There are multiple benefits associated with use of RA and analgesia including decreased length of hospital stay, better neurological evaluation, safer patient transport, decreased requirement of resources as compared to general anaesthesia, early mobilization, speedy return to oral nutrition and lesser rehabilitation costs. In addition to patient benefits of RA, it has also been associated with significant reduction in healthcare costs.

Technique to deliver RA can be either through anatomic landmarks or Ultrasound (US) guidance. A few studies have suggested that local anaesthetic injection using US may reduce complication rates compared to anatomic landmark guided injection. In a resource limited operational setting anatomic landmark technique may be more advantageous due to unavailability of costly US equipment and additional training.

Our study was conducted in a resource limited setting of a peripheral hospital, being first in chain of evacuation of combat casualties in conflicted zone of North India. This military Zonal hospital located in the northern sector receives trauma cases from forward combat and counter-insurgency areas and provides definitive surgical management of these cases. This retros- pective observational study was taken up to establish pattern of military trauma cases / combat casualties in operational area and type of anaesthesia employed for surgical management of the same cases (primary objective). This study was also aimed to compare the type of anaesthesia used as per the region of body involved, RA vs GA for management of peripheral limb injuries and the type of surgeries being done in military trauma.

\section{MATERIALS AND METHODS}

A retrospective observational study was done of all military trauma cases in a periphery zonal hospital deployed in operational area. All trauma/ combat casualties were included over a period of one year from Oct 2018 to Oct 2019 and data was segregated based on type of mechanism of trauma, limb injuries involved, and choice of anaesthesia given based on type of surgery. A total of 371 patients were included in this study over a period of one year and data was summarised in terms of percentage using MS- Excel software. Institutional and Ethics committee clearance was taken before beginning of the study. The data was collected from hospital records including admissions register, operation theatre register and surgical ward records. Fatal casualties were excluded from the study (these are the cases which were brought in dead to the hospital). This was a retrospective study aimed to establish pattern of trauma and type of anaesthesia employed for its surgical management. The outcomes of the type of each type of anaesthesia is out of bound to this study. Outcomes of the anaesthesia is not the objective of the study. However, this study can be a way forward for the interventional studies on the efficacy of the techniques.

\section{RESULTS}

\section{Demographic profile}

A total of 371 soldiers were considered in this study. The age ranged from 19 yrs to 53 yrs with an average of 31.76 yrs. No specific regiment or geographical belt was specified while analysing the subjects.

\section{Cause of Injuries}

Of the total 371 combat casualties, 161 patients (43.4\%) had splinter injuries with grenade blast being the most common type of injury, followed by gunshot wounds, 148 cases (39.9\%). Other injuries included mine blast, $42(11.3 \%)$ and miscellaneous including road traffic accidents comprised remaining 20 cases (5.4\%) (Figure 1). 


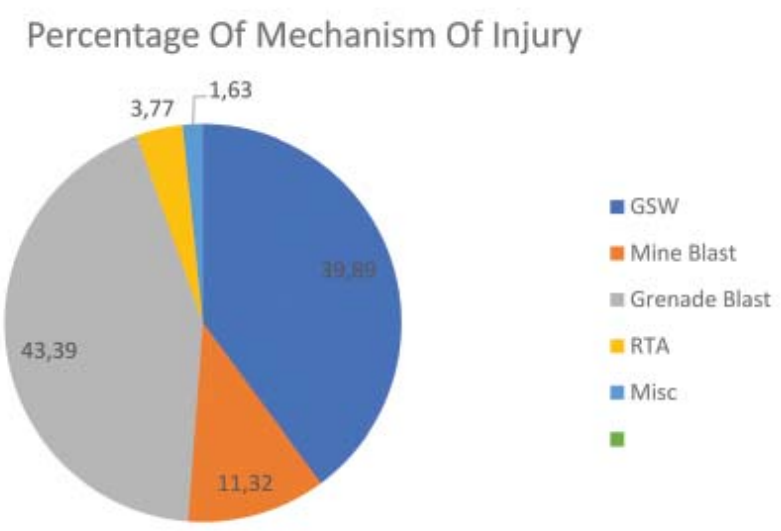

Figure 1. Percentage of mechanisms of injury.

\section{Body region involved in combat trauma}

As expected, limb injuries dominated the body regions involved, upper and lower limbs both having almost equal involvement; 175 upper limb and 176 lower limb cases. Of the 175 upper limb cases, maximum injuries involved were of forearm, 72 (19.4\%) cases. Hand injuries and those involving above elbow were again similar, $50(13.5 \%)$ and $53(14.3 \%)$ respectively. For the lower limb out of 176 cases, maximum injuries were of legs $93(25.1 \%)$, followed by $62(16.7 \%)$ cases of above knee injury. Only 21 cases (5.7\%) involved injury to feet. Remaining 20 (5.4\%) cases involved head trauma, facial injuries, thoracic and abdominal injuries (Figure 2).

\section{Percentage of type of body region}
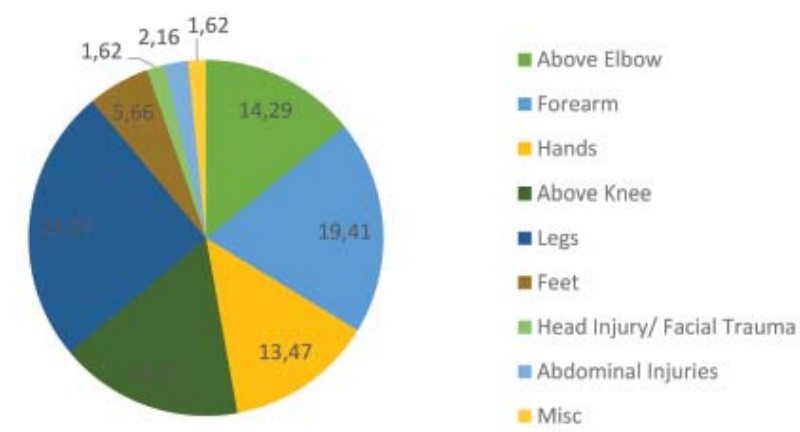

Figure 2. Percentage of injuries as per body region.

\section{Type of surgery and anaesthesia used}

Of all the surgeries, wound debridement was the most common type of surgery being performed, 144 cases $(38.8 \%)$, followed by orthopaedic procedures like ORIF \& plating 110 (29.7\%), CRIF 53 (14.3\%) and implant removal 23 (6.2\%). Other cases included exploratory laprotomy 11 (2.9\%), amputation $6(1.6 \%)$ and miscellaneous remaining surgeries were 24 (6.5\%). Majority of the patients belonged to either ASA1, 173patients (46.7\%) or ASA 2, 138 (37.2\%). Due to nature of injuries and predominant involvement of limbs, regional anaesthesia was used most commonly, 174 cases (46.9\%), regional anaesthesia was supplemented with TIVA in 19 (5.1\%)cases, sub arachnoid block in

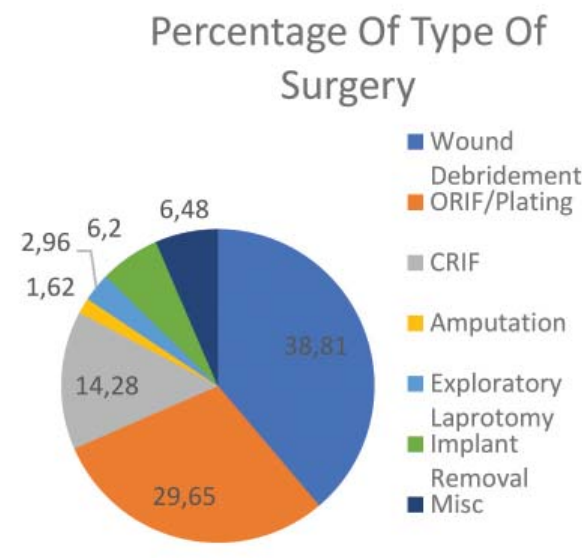

\section{Percentage Of Type Of Anaesthesia}

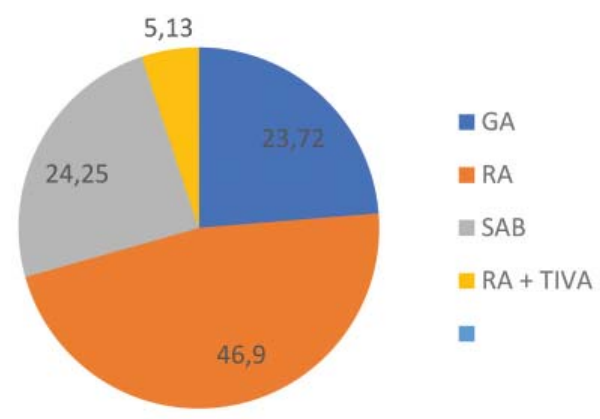

Figure 3. Percentage of type of surgery \& anaesthesia used. 
Bala Chandran NAMBIAR et al.

Table 1.Type of anaesthesia as per body region

\begin{tabular}{|l|c|c|c|c|c|}
\hline \hline Body Region & Number & RA & GA & RA+TIVA & SAB \\
\hline Upper Limb & $175(47.2)$ & $138(78.8)$ & $28(16)$ & $9(5.2)$ & \\
\hline Above Elbow & $53(14.3)$ & $40(23.4)$ & $11(11.9)$ & $2(10)$ & \\
\hline Forearm & $72(19.4)$ & $55(32.2)$ & $14(15.2)$ & $3(15)$ & \\
\hline Hands & $5013.5)$ & $43(25.1)$ & $3(3.3)$ & $4(20)$ & \\
\hline Lower Limb & $176(47.4)$ & $33(18.7)$ & $44(25)$ & $11(6.3)$ & $88(50)$ \\
\hline Above Knee & $62(16.7)$ & $2(1.2)$ & $25(27.2)$ & $1(5)$ & $34(38.6)$ \\
\hline Legs & $93(25.1)$ & $29(16.9)$ & $14(15.2)$ & $6(30)$ & $44(50)$ \\
\hline Feet & $21(5.6)$ & $2(1.2)$ & $5(5.4)$ & $4(20)$ & $10(11.4)$ \\
\hline Others & $20(5.4)$ & & $20(100)$ & & \\
\hline Head Injury/ Facial Trauma & $6(1.6)$ & & $6(6.5)$ & & \\
\hline Abdominal Injuries & $8(2.2)$ & & $8(8.7)$ & & \\
\hline Misc & $6(1.6)$ & & $6(5.5)$ & & \\
\hline
\end{tabular}

$90(24.25 \%)$ and general anaesthesia was used only in 88 (23.7\%) (Figure 3).

\section{Type of anaesthesia as per body region}

Type of anaesthesia used as per body region is shown in Table 1 and Figure 4. As is evident from the table maximum upper limb injuries were operated under Regional anaesthesia (78.8\%), and maximum lower limb injuries were performed under sub arachnoid block (50\%), while injuries involving body regions other than limbs were performed exclusively under GA (Table 1, Figure 4).

\section{Type of regional anaesthesia used}

Of the various RA techniques, Supra-clavicular Block was most commonly used in upper limb injuries (40.5\%), followed by Interscalene block (6.45\%). SAB was the most common technique used for lower limb injuries (31.5\%), followed by femoral and sciatic block (15.05\%) (Table 2, Figure 5).

Type of anaesthesia as per body region

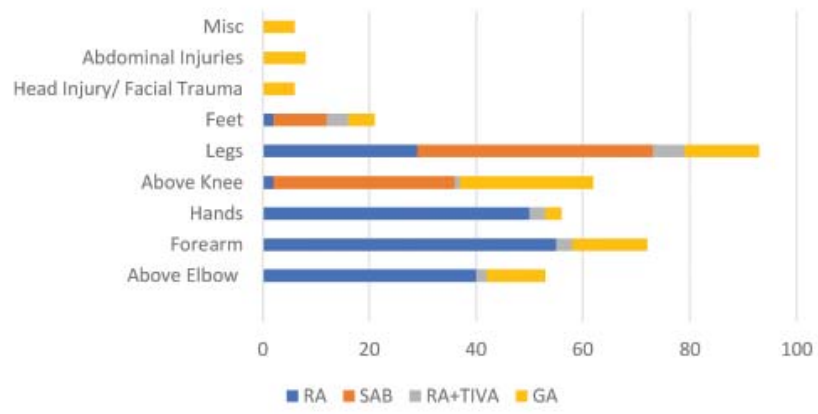

Figure 4. Percentage of type of anaesthesia as per body region.

\section{Complications}

There were minimum procedural complications associated with Regional Anaesthesia techniques. No incidence of Pneumothorax or vascular injury was reported in upper limb blocks, however, there were 4 cases $(1.07 \%)$ of unilateral ptosis associated with interscalene block, which resolved spontaneously. For lower limb

\begin{tabular}{l}
\hline Table 2. Type of regional anaesthesia \\
\begin{tabular}{|l|c|c|}
\hline Type of RA & Number & Percentage (\%) \\
\hline Supraclavicular Block & 113 & 40.5 \\
\hline Infraclavicular Block & 9 & 3.23 \\
\hline Interscalene Block & 18 & 6.45 \\
\hline Axillary Block & 3 & 1.08 \\
\hline Wrist Block & 4 & 1.43 \\
\hline Ankle Block & 2 & 0.72 \\
\hline Femoral + Sciatic Block & 42 & 15.05 \\
\hline SAB & 88 & 31.54 \\
\hline Total & 279 & 100 \\
\hline
\end{tabular}
\end{tabular}

\section{Percentage Of Type Of Block}

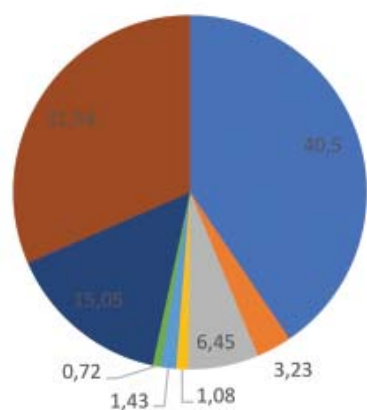

- Supraclavicular Block

- Infraclavicular Block

interscalene Block

in Axillary Block

wrist Block

Ankle Block

- Femoral+Sciatic Block

a $\mathrm{SAB}$

Figure 5. Percentage of various regional anaesthesia blocks. 
injuries 42 patients $(23.8 \%)$ had associated hypotension following $\mathrm{SAB}$, which was managed effectively with fluid resuscitation and vasopressors. Five patients had failed spinal and had to be converted to GA and ten patients had urinary retention managed with bladder catheterisation. There was a single case of accidental Dural tap while placing Epidural catheter and two cases reported to have PDPH which were managed conservatively. There was nil incidence of Compartment Syndrome, permanent nerve damage or death reported following regional anaesthesia in trauma in our study.

\section{DISCUSSION}

Most of the literature available on combat trauma comes from international data during Operation Enduring Freedom and Operation Iraqi Freedom. Despite having conflicts and counterinsurgency operations spanning over decades, very few studies in Indian scenario have analysed injuries related to military trauma. There is further scarcity of Indian literature reviewing anaesthesia techniques in the management of trauma and to the best of our knowledge no study has so far evaluated anaesthesia techniques in combat and military trauma of Indian Armed Forces scenario. Our study is a retrospective observational study which analyses the type of injuries suffered by military personnel admitted to a tertiary care hospital of the Indian Armed Forces in the setting of intense counter insurgency operations. It also evaluates the use of various Anaesthesia techniques according to the injury and body part involved. Being a retrospective study, there is an inherent risk of error in data collection from various sources. Sincere effort has been made to cross check all the records to avoid any discrepancy.

In our study, of the total 371 combat casualties maximum patients had splinter injuries with grenade blast being the most common type of injury (43.4\%), followed by gunshot wounds (39.9\%). Other injuries included mine blast (11.3\%) and miscellaneous including road traffic accidents (5.4\%). Our study has findings similar to those of various other authors, namely
Rai et al. ${ }^{16}$, Belmont $\mathrm{PJ} \mathrm{Jr}{ }^{17}$ and Owens $\mathrm{BD}^{18}$, which mention majority of combat injuries due to explosive devices including grenades, IEDs, mortar fire and other fragmentation devices in their literature.

Due to nature of injuries and predominant involvement of limbs, regional anaesthesia was used most commonly (46.9\%), regional anaesthesia was supplemented with TIVA in $19(5.1 \%)$ cases, sub arachnoid block was used in in $90(24.25 \%)$ cases of lower limb injuries and general anaesthesia was used in $88(23.7 \%)$ cases involving thoracic-abdominal injuries and head injuries.

A study by Gallagher and colleagues emphasises on the utility of RA for acute pain management in combat related extremity injuries. A retrospective study by Stojadinovic included 126 military trauma patients and reported significant reduction in pain intensity over prolonged duration with use of RA5. Buckenmaier CC mentions role of RA throughout the various stages of management of combat casualties, including initial pain management, evacuation to tertiary centre and even rehabilitation ${ }^{11}$.

Our study also reported significantly higher use of regional anaesthesia in case of combat related trauma to extremities. It is therefore in accordance to the existing literature and current guidelines meeting the standards of combat casualty care.

\section{RECOMMENDATIONS}

This is a case sheet review retrospective study. In further studies prospective intervention can be done to study the patient outcomes based on type of regional anaesthesia technique used.

Compliance with ethics requirements: The authors declare no conflict of interest regarding this article. The authors declare that all the procedures and experiments of this study respect the ethical standards in the Helsinki Declaration of 1975, as revised in 2008(5), as well as the national law. Informed consent was obtained from all the patients included in the study. 


\section{References}

1. Butler FK, Kotwal RS, Buckenmaier CC, et al: A triple-option analgesia plan for tactical combat casualty care: TCCC guidelines change 13-04. Spec Oper Med 2014; 14(1): 13-25.

2. Wedmore IS, Butler FK: Battlefield analgesia in tactical combat casualty care. Wilderness Environ Med 2017; 28(2S): S109-16.

3. Shackelford SA, Fowler M, Schultz K, et al: Prehospital pain medication use by U.S. Forces in Afghanistan. Mil Med 2015; 180(3): 304-9.

4. Polomano RC, Buckenmaier CC, Kwon KH, et al: Effects of lowdose IV ketamine on peripheral and central pain from major limb injuries sustained in combat. Pain Med 2013; 14(7): 1088100.

5. Stojadinovic A, Auton A, Peoples GE, et al: Responding to challenges in modern combat casualty care: innovative use of advanced regional anesthesia. Pain Med 2006; 7(4): 330-8.

6. Buckenmaier C, Mahoney PF, Anton T, et al: Impact of an acute pain service on pain outcomes with combat-injured soldiers at Camp Bastion, Afghanistan. Pain Med 2012; 13(7): 919-26.

7. Pozek J-PJ, Beausang D, Baratta JL, et al. The acute to chronic pain transition: can chronic pain be prevented? Med Clin North Am 2016;100:17-30.

8. Ilfeld BM: Continuous peripheral nerve blocks: a review of the published evidence. Anesth Analg 2011; 113(4): 904-25.

9. Hoge CW, Terhakopian A, Castro CA, et al. Association of posttraumatic stress disorder with somatic symptoms, health care visits, and absenteeism among Iraq war veterans. Am J Psychiatry 2007;164:150-3

10. Bowman WJ, Nesbitt ME, Therien SP. The effects of standardized trauma training on prehospital pain control: have pain medication administration rates increased on the battle eld? J Trauma Acute Care Surg 2012;73.

11. Buckenmaier CC, Rupprecht C, McKnight G, et al. Pain following battle field injury and evacuation: a survey of 110 casualties from the wars in Iraq and Afghanistan. Pain Med 2009;10:148796.

12. Holbrook TL, Galarneau MR, Dye JL, et al. Morphine use after combat injury in Iraq and post-traumatic stress disorder. N Eng J Med 2010:362:110-7.

13. Rastogi A, Gyanesh P, Nisha S, et al: Comparison of general anaesthesia versus regional anaesthesia with sedation in selected maxillofacial surgery: a randomized controlled trial. J Craniomaxillofac Surg 2014; 42(3): 250-4.

14. Narouze SN, Provenzano D, Peng P, et al. The American Society of Regional Anesthesia and Pain Medicine, the European Society of Regional Anaesthesia and Pain Therapy, and the Asian Australasian Federation of Pain Societies Joint Committee recommendations for education and training in ultrasoundguided interventional pain procedures. Reg Anesth Pain Med. 2012:37(6):657-64.

15. Walker KJ, McGrattan K, Aas-Eng K, Smith AF. Ultrasound guidance for peripheral nerve blockade. Cochrane Database Syst Rev. 2009;4:CD006459.

16. Rai KM, Kale R, Mohanty SK, Chakrabarty A, Waghray MR, Kumar $R$, et al. Treatment of casualties in a forward hospital of Indian army: Nine year experience. Med $\mathrm{J}$ Armed Forces India 2004;60:20-4

17. Belmont PJ Jr, McCriskin BJ, Sieg RN, Burks R, Schoenfeld AJ. Combat wounds in Iraq and Afghanistan from 2005 to 2009. J Trauma Acute Care Surg 2012;73:3-12.

18. Owens BD, Kragh JF Jr., Wenke JC, Macaitis J, Wade CE, Holcomb JB. Combat wounds in operation Iraqi freedom and operation enduring freedom. J Trauma 2008;64:295-9. 19. Gallagher RM, et al. Reg Anesth Pain Med 2019;0:1-8. doi:10.1136/ rapm-2019100773. 